\title{
TECENDO SABERES E CONSTRUINDO ENTENDIMENTOS SOBRE PRÁTICAS DE LEITURA À LUZ DA PRÁTICA EXPLORATÓRIA ${ }^{1}$
}

\begin{abstract}
Andréia Mello Rangel ${ }^{2}$
Resumo: Neste artigo, apresento um recorte da minha pesquisa de mestrado, na qual busquei, ao construir um movimento de aprendizagem colaborativa com os meus alunos, trabalhar para entender as práticas de leitura dos aprendizes. Este estudo apoia-se nos princípios balizadores da Prática Exploratória (ALLWRIGHT, 2005) e na teoria postulada por Vygotsky (2003), na medida em que destaca a importância da interação dos sujeitos no processo de ensino-aprendizagem. Esta pesquisa aponta para o fato de que as atividades que fomentam a formação do leitor devem considerar não apenas o trabalho com a língua (TRAVAGLIA, 2009) e com os gêneros discursivos (BAKHTIN, 2011), mas precisam promover também o diálogo entre as múltiplas epistemes coexistentes dentro do ambiente escolar, de modo que não apenas os conhecimentos hegemônicos tenham espaço dentro da sala de aula.
\end{abstract}

Palavras-chave: Leitura. Prática Exploratória. Atividade Pedagógica com Potencial Exploratório. Discurso.

Introdução

Em minha atuação pedagógica, determinadas questões a respeito do trabalho com a leitura e do fomento à formação do leitor sempre me chamaram especial atenção. Dentre essas questões, destaco o distanciamento existente entre a leitura - praticada por muitos de meus alunos - (muitas vezes ignorada pela escola) e o que é apresentado pelos professores para eles como leitura dentro do ambiente escolar. Um dos papéis que a minha atividade como professora de língua e de literatura do ensino fundamental e médio me impõe - o de promover o incentivo à leitura do texto escrito, por meio do fomento à formação efetiva do aluno leitor-autor - também por vezes constituiu motivo de reflexão sobre a minha prática docente no que concerne ao trabalho com a leitura.

Assim, reflexões a respeito das atividades que têm como foco a leitura constituíram o fio condutor dos meus estudos no mestrado. A pesquisa, defendida em novembro de 2016, apresentou como um dos principais objetivos a construção de entendimentos acerca das práticas de leitura dos

\footnotetext{
${ }^{1}$ O presente texto foi baseado na dissertação de mestrado: RANGEL, Andréia M. "Professora, eu leio, quer ver?" Um diálogo exploratório com as práticas de leitura dos aprendizes. 2016. (Mestrado em Letras). Faculdade de Formação de Professores da Universidade do Estado do Rio de Janeiro - FFP/UERJ. Orientadora: Profa Drạ Isabel Cristina Rangel Moraes Bezerra.

${ }^{2}$ Mestre em Letras pelo Programa de Mestrado Profissional em Letras - FFP/UERJ. Professora da Rede Estadual de Ensino do Rio de Janeiro. Integra o corpo técnico da Subsecretaria de Educação da Fundação Municipal de Educação de Niterói na assessoria pedagógica e na área de língua portuguesa. E-mail: profandreiamello@gmail.com
} 
alunos e das alunas, os quais constituíram uma turma do nono ano de escolaridade do ensino fundamental de uma escola da Rede Estadual de Ensino do Rio de Janeiro. A construção de entendimentos a respeito das práticas de leitura dos aprendizes foi conduzida pelo diálogo, pela escuta sensível e pela tessitura de saberes.

Os dados da pesquisa apresentados e destacados neste artigo foram gerados a partir de um processo de ensino e aprendizagem que considerou o diálogo entre os múltiplos conhecimentos que coexistem dentro do ambiente escolar. Assim, não apenas os conhecimentos hegemônicos, legitimados pelos currículos escolares, tiveram espaço dentro da sala de aula.

Na busca de envolver os aprendizes na ação do "trabalhar para entender", formulei, com o auxílio dos meus alunos, atividades inspiradas na abordagem para o ensino, a pesquisa e a reflexão da Prática Exploratória (ALLWRIGHT, 2005). Essas atividades se constituíram como APPE - Atividades Pedagógicas com Potencial Exploratório (ALLWRIGHT, 2005; MORAES BEZERRA, MILLER, CUNHA, 2007). Dessa forma, contemplaram tudo o que envolveu o processo educacional na pesquisa: a escola, minha condição de professora, os meus alunos e nossas vivências. Assim, não somente o trabalho com a língua (TRAVAGLIA, 2009) e com os gêneros discursivos (BAKHTIN, 2011) ganhou destaque. As contribuições da teorização vygotskyana também ficaram evidentes nesse estudo, o qual destacou a importância da interação dos sujeitos no processo de ensino-aprendizagem.

Neste trabalho, a leitura é apresentada sob a égide da diversidade e em uma perspectiva histórica, cultural, múltipla e heterogênea (STREET, 2014; SOARES, 2012; ROJO, 2009; ABREU, 2000). E o currículo escolar, neste estudo, é considerado um espaço em que haja a tessitura dos saberes dos agentes da aprendizagem. Percebe-se, dessa forma, aprendizes e professora como produtores de conhecimento e como agentes do ensinar e do aprender. Importa ressaltar que, assim, este artigo se configura como uma possibilidade de reflexão sobre uma política de trabalho não apenas para a leitura, mas com as práticas de leitura dos aprendizes e da professora.

\section{Pressupostos teóricos}

Todo educador elege, ainda que de modo inconsciente, uma concepção de linguagem para direcionar e orientar o seu trabalho. Geraldi (2012) aponta três concepções de linguagem que podem balizar o trabalho do professor: a linguagem como expressão do pensamento, a linguagem como instrumento de comunicação e a linguagem como forma de interação (GERALDI, 2012). 
A teoria que compreende a linguagem como um processo de interação preconiza que os sujeitos, ao interagirem, o fazem atravessados por questões histórias, culturais, sociais, ideológicas, as quais os constituem no espaço-tempo em que se encontram. Dessa forma, a linguagem é situada como um lugar de possíveis conflitos e dissensos, visto que é na interação entre os sujeitos que ela se realiza. Para Geraldi (2012), de acordo com essa concepção

mais do que possibilitar uma transmissão de informações de um emissor a um receptor, a linguagem é vista como um lugar de interação humana. Por meio dela, o sujeito que fala pratica ações que não conseguiria levar a cabo, a não ser falando; com ela o falante age sobre o ouvinte, constituindo compromissos e vínculos que não preexistiam à fala (GERALDI, 2012, p. 41).

Neste trabalho, a escolha da concepção que entende a linguagem como processo de interação possibilitou-me abraçar as leituras realizadas pelos meus alunos e pelas minhas alunas e permitiu que eu estabelecesse com eles e com elas uma relação, de fato, dialógica.

O acolhimento, em sala de aula, das práticas de leitura dos aprendizes também foi favorecido pelo fato de a leitura ser entendida sob a égide da diversidade e em uma perspectiva histórica e cultural. Abreu (2000, p. 121) afirma que "a diversidade é constitutiva do ato de ler" e aponta para a ideia, de certo modo recente, de associar a figura de um bom leitor à condição de ler muito e ler textos diversos. De acordo com a autora

Durante séculos a quantidade de impressos disponível era pequena, seu preço, elevado, e o livro - mesmo que não tratasse de tema religioso - era muitas vezes sacralizado. O bom leitor, era aquele que lia pouco, relia com freqüência e meditava muito sobre os escritos (ABREU, 2000, p.123).

Ao seguir com as reflexões sobre leitura a partir de um viés histórico, Abreu (2000, p. 123) destaca que "mesmo hoje nem todas as pessoas leem e escrevem da mesma maneira" e que "alguns modos de ler podem parecer superados, mas só o serão se tomarmos para análise apenas as camadas mais cultas da sociedade" (ibid.). Assim, a autora nos faz observar a leitura não apenas pela perspectiva histórica, mas também pelo viés sociológico ao afirmar que "as formas de ler e avaliar os textos variam se se considerarem diferentes classes sociais, regiões, etnias, etc" (ABREU, 2000, p. 123).

A partir das contribuições de Abreu (2000), acredito ser pertinente a seguinte reflexão: Como é possível ao professor conhecer as práticas de leitura dos alunos sem trabalhar efetivamente com a 
leitura, ou seja, sem trabalhar a partir de dados reais sobre como o ler acontece na vida do aluno, sem restringir-se, tão somente, a falar sobre essa temática?

Penso não ser possível conhecer as práticas e gostos de leitura dos alunos sem reconhecer e considerar, dentro da sala de aula, os letramentos dos educandos. Opto por adotar a palavra letramentos, no plural, por atribuir a esse conceito uma dimensão social. Assim, letramentos "se contrapõe à ênfase dominante num 'Letramento' único e 'neutro', com L maiúsculo e no singular" (STREET, 2014, p. 18).

Nesse sentido, esse conceito assume um enfoque sociológico e cultural, de acordo com o que observa Soares (2012) "letramento não é pura e simplesmente um conjunto de habilidades individuais; é o conjunto de práticas sociais ligadas à leitura e à escrita em que os indivíduos se envolvem em seu contexto social" (SOARES, 2012, p. 72). Ao adotar o termo letramentos, alinho-me também à perspectiva dos letramentos múltiplos (ROJO, 2009), ou seja, procuro deixar de "ignorar ou apagar os letramentos das culturas locais de seus agentes (professores, alunos, comunidade escolar)" e coloco esses letramentos "em contato com os letramentos valorizados, universais e institucionais" (ROJO, 2009, p. 107). Dessa forma, busco considerar saberes outros, que ficam à margem, colocando-os em diálogo com os saberes institucionalizados e legitimados, mitigando, assim, a assimetria existente entre eles. Com essa atitude, observo o caráter plural e social que o conceito de letramento pode assumir.

Alinho-me, ainda, ao enfoque de currículo visto sob a perspectiva de conhecimentos em redes (ALVES, 2002 apud FERRAÇO, 2015, p. 10), a fim de que o diálogo entre os saberes seja favorecido. Ferraço (2015) esclarece esse enfoque a respeito do tema currículo:

Ao participarem da experiência curricular cotidiana, mesmo que supostamente seguindo materiais curriculares preestabelecidos, professores e alunos tecem alternativas práticas com os fios que as redes das quais fazem parte, dentro e fora da escola, Ihes fornecem (FERRAÇO, 2015, p. 10).

Penso que ao entender o currículo sob a perspectiva supracitada, me afasto do lugar de reprodutora e/ou de implementadora de um programa educacional e me aproximo do lugar de coautora de uma prática pedagógica, visto que os conhecimentos estipulados nos currículos escolares são tecidos com os conhecimentos presentes no cotidiano escolar. Dessa forma, problematizo, de maneira colaborativa com os aprendizes, as propostas prescritivas oficiais fazendo 
com que os conhecimentos presentes na sala de aula e os que são legitimados pelos currículos escolares não sejam vistos de maneira dicotômica, mas complementares.

Ao me aproximar das práticas de leitura dos meus alunos e das minhas alunas e estabelecer com eles e com elas um diálogo exploratório, penso ter ressaltado, na relação com os educandos, um aspecto fundamental no processo de conhecimento: a afetividade, pois compreendi os meus alunos não apenas como seres que pensam e raciocinam, mas como pessoas que se sensibilizam, sentem, se emocionam, têm preferências. Dessa forma, ressaltei a importância dessa compreensão na construção de atividades que, de fato, considerem essas questões no processo de ensinar e de aprender, seguindo a perspectiva dos estudos de Vygotsky, os quais ressaltam que cognição e afeto não se encontram dissociados no ser humano, mas, ao se inter-relacionarem, exercem influências recíprocas ao longo de toda a história de desenvolvimento dos sujeitos (REGO, 1995).

\section{Metodologia}

A pesquisa qualitativa, própria das ciências sociais, orienta este estudo, pois "é uma atividade situada que localiza o observador no mundo. Consiste em um conjunto de práticas materiais e interpretativas que dão visibilidade ao mundo" (DENZIN; LINCOLN, 2006, p. 17). Assim, para o pesquisador que se ancora na abordagem qualitativa, as questões sociais, históricas e culturais estão interligadas no processo de compreensão do que ele se propõe investigar. Desse modo, o ato de compreender o que está ao alcance do pesquisador qualitativo considera as marcas sociais que atravessam a realidade pesquisada. A Prática Exploratória, embora não seja considerada uma metodologia de pesquisa, se consolida como uma abordagem inclusiva para o ensino e para a pesquisa (MORAES BEZERRA, 2012) e está inserida no paradigma qualitativo.

Idealizada por Dick Allwright, na década de 90, a Prática Exploratória surgiu como uma resposta aos modelos de pesquisa vigentes à época (e existentes também nos dias atuais), os quais preconizam uma pesquisa de terceira pessoa [third-partyresearch] (ALLWRIGHT e HANKS, 2009), na qual o pesquisador precisa cuidar para não interferir na geração de dados e no contexto de pesquisa, em uma lógica que postula a construção de uma neutralidade entre pesquisador e pesquisados. Moraes Bezerra (2012) esclarece que, inicialmente, a Prática Exploratória surgiu como uma crítica às pesquisas realizadas em salas de aula de língua estrangeira, as quais se alinhavam a uma proposta que Allwright e Hanks (2009) mais tarde denominaram parasítica [parasitic research]. Essa forma de pesquisar é evidente em uma proposta que se caracteriza pela ida do pesquisador ao contexto, para obter dados e, em seguida, retirar-se daquele espaço, de modo que desenvolva o seu trabalho de pesquisa e não contribua - ou contribua minimamente - para que os pesquisados gerem também entendimentos acerca do "problema" investigado.

Allwright apontou para a construção de uma prática reflexiva e de inclusão, de modo que todos os envolvidos no processo de ensinar e de aprender se sentissem convidados e encorajados a serem agentes e praticantes desse processo. Assim, a qualidade de vida do grupo envolvido na pesquisa orientada pela Prática Exploratória é construída à medida que, colaborativamente, se busque entendimentos de maneira dinâmica, respeitosa e reflexiva acerca das questões que pertencem ao e que se refletem no grupo.

Dessa forma, a Prática Exploratória se apresenta como uma possibilidade de unir ensinoaprendizagem-pesquisa, de modo que os praticantes de todo esse processo estejam mais atentos às questões que envolvem esse caminhar e juntos trabalhem para construir entendimentos acerca da 
forma como atuam nesse movimento e sobre as demais questões que o envolvem. Assim, os praticantes da Prática Exploratória não agem para mudar algo - no sentido de uma mudança programada e técnica, realizada para solucionar determinado "problema"- mas para entenderem de que forma o processo de ensino e aprendizagem acontece dentro de determinado espaço afetado por questões do mundo que o circunda. Assim, determinada mudança poderá acontecer, pois, como observa Allwright, a Prática Exploratória "toma a mudança como algo inevitável e de que, a princípio, não há razão para ser contra ou a favor" (ALLWRIGHT, 2002 apud MORAES BEZERRA, 2007, p. 58). No entanto, o ensino e a pesquisa orientados pela Prática Exploratória observam a questão da mudança sob o enfoque do entendimento, no sentido de uma perspectiva "de que compreender a vida em sala de aula é primordial e que todas as propostas de mudança devem ser vistas sob essa perspectiva" (ALLWRIGHT, 2002 apud MORAES BEZERRA, 2007, p. 58).

Assim, Moraes Bezerra, Miller e Cunha (2007), considerando o contexto escolar - enfoque que interessa a esta pesquisa - conceituam, neste momento histórico, a Prática Exploratória como

Uma maneira indefinidamente sustentável em que professores e alunos, dentro de suas salas de aula e enquanto trabalham no processo de aprender e de ensinar se engajam para desenvolver o seu entendimento da vida na sala de aula (MORAES BEZERRA; MILLER; CUNHA, 2007, p. 193-194).

São princípios norteadores da Prática Exploratória:

- Priorizar a qualidade de vida.

- Trabalhar para entender a vida na sala de aula ou em outros contextos profissionais.

- Envolver todos nesse trabalho.

- Trabalhar para a união de todos.

- Trabalhar para o desenvolvimento mútuo.

- Integrar este trabalho com as práticas de sala de aula ou com outras práticas profissionais.

- Fazer com que o trabalho para o entendimento e a integração sejam contínuos (MORAES BEZERRA; MILLER; CUNHA, 2007, p.194 - Grifos das autoras).

Esses princípios são balizadores do processo de ensino e de aprendizagem e da pesquisa orientados pela Prática Exploratória. Eles se operacionalizam à medida que a reflexão, o encorajamento para a participação de todos no trabalho, o respeito e o cuidado configurem oportunidades para que os envolvidos no processo de ensinar-aprender-pesquisar percebam-se agentes exploratórios desse caminhar e sintam-se incentivados a continuarem construindo a prática da reflexão dentro e fora do contexto escolar e/ou de pesquisa (MILLER et al, no prelo).

Para isso, um aspecto relevante para a Prática Exploratória são as denominadas oportunidades de aprendizagem [learning opportunities] (ALLWRIGHT, 2005). Esse construto relaciona-se às "situações que proporcionam circunstâncias favoráveis à socioconstrução de conhecimento, seja este relacionado às dimensões social, afetiva, cognitiva e subjetiva" (MILLER et al, no prelo). Allwright (2005) sinaliza que as oportunidades de aprendizagem se distanciam dos "tópicos para ensinar" e aproximam-se da multiplicidade de possibilidades de aprendizagem que, de maneira não planejada, podem acontecer no grupo dos praticantes exploratórios.

Penso que é no momento de perceber as possíveis oportunidades de aprendizagem que o olhar atento e a escuta sensível se tornam mais evidentes na prática do professor exploratório. E para 
praticar esse olhar e escuta sensíveis, aspectos caros e fundamentais para o fazer exploratório, acredito que as cinco proposições sobre os aprendizes, apresentadas por Allwright e Hanks (2009), precisam ser observadas e consideradas. Os referidos autores postulam que

1. Os aprendizes são pessoas únicas que aprendem e se desenvolvem melhor quando o fazem à sua maneira.

2. Os aprendizes são seres sociais que aprendem e se desenvolvem melhor quando estão em um ambiente de apoio mútuo/quando se apoiam entre si/uns nos outros.

3. Os aprendizes são capazes de levar seu aprendizado a sério.

4. Os aprendizes são capazes de tomar suas próprias decisões.

5. Os aprendizes são capazes de se desenvolverem como construtores do seu processo de aprendizagem (MILLER et al, no prelo).

Assim, para auxiliar o professor e os alunos a realizar um trabalho investigativo e reflexivo acerca das questões que os envolvem, Allwright desenvolveu a ideia a respeito das Atividades Pedagógicas com Potencial Exploratório - APPE (MORAES BEZERRA, 2007). Moraes Bezerra (2007) também denomina essas atividades como ARPE - Atividades de Reflexão com Potencial Exploratório. A autora esclarece que essas atividades são as quais o professor já desenvolve em sala de aula. No entanto, à luz dos princípios norteadores da Prática Exploratória, elas ganham novos contornos por professores exploratórios durante o seu fazer pedagógico, a fim de que esses professores se envolvam com os seus alunos em um processo de reflexão (MORAES BEZERRA, 2012). A partir da inserção de puzzles, tais atividades podem ser um instrumento para levar os aprendizes não apenas a aprender sobre algum ponto do conteúdo programático, mas a refletirem a respeito de questões que os envolvem dentro e fora da sala de aula.

Os puzzles (MORAES BEZERRA, 2007), outro construto também desenvolvido por Allwright, são questionamentos que intrigam e mobilizam professores e alunos no cotidiano escolar e são levantados pelos próprios professores e alunos, praticantes do processo de ensinar e de aprender. Moraes Bezerra (2007, p. 136 - Grifo da autora) ressalta que esse construto se refere aos "porquês a serem respondidos envolvendo professores e alunos ou professores e consultor ou qualquer outro grupo que mantenha relações (profissionais) em um dado contexto institucional".

Os construtos e as proposições da Prática Exploratória orientam este trabalho e o meu fazer docente. O fio condutor inclusivo e reflexivo dessa abordagem para o ensino e para a pesquisa me auxilia na construção de uma pesquisa e de uma prática pedagógica que criem ambientes de reflexão e de coconstrução, de modo que eu me afaste de uma postura tecnicista, pragmática, não autoral e distante da realidade em que me encontro na sala de aula em que atuo e no meu fazer como professora pesquisadora. 
Dessa forma, este estudo, através do fio condutor reflexivo e inclusivo da Prática Exploratória, não busca soluções, mas entendimentos a respeito das questões - dos puzzles - que o envolvem. Assim, não me afasto dos conteúdos a serem trabalhados em minha atividade como professora pesquisadora praticante exploratória, mas os ressignifico e os vejo sob a perspectiva da reflexão e da inclusão.

\section{Análise de dados}

A elaboração das APPE com meus alunos constituiu um grande desafio. Os meus alunos e as minhas alunas pareciam não compreender a importância da participação de todos na elaboração das atividades, embora fossem sempre incentivados a partilharem suas impressões a respeito do que havia sido proposto. Inicialmente, poucos aprendizes se manifestavam. Ainda que eu buscasse vivenciar os princípios da Prática Exploratória ao envolver os alunos no "trabalhar para entender" e ao fomentar um espaço de reflexão, de encorajamento, de escuta sensível e de olhar atento, os alunos pareciam não estar acostumados com espaços de escuta de seus anseios e de suas impressões sobre aprendizagem na escola. Dessa forma, era possível observar um estranhamento por parte dos alunos com relação à mudança de dinâmica na sala de aula.

Ter sido mediadora da elaboração das APPE também constituiu um grande desafio para mim. Embora sempre tenha sido de extrema importância ter uma escuta e um olhar sensíveis aos meus alunos, realizar essa atividade de maneira sistemática, de modo a construir com eles uma sequência de atividades pedagógicas, foi uma novidade e uma oportunidade de aprendizagem para mim (ALLWRIGHT, 2005) também. Aliar a docência à pesquisa constituiu outro desafio e aprendizagem. Agregar ensino-pesquisa-reflexão, proposta da Prática Exploratória, e registrar através de imagens aqueles momentos foi provocante e laborioso na medida em que tais atividades precisavam ser feitas durante as aulas, não obstante as dificuldades do cotidiano escolar: salas de aula quentes e desconfortáveis, dificuldade de concentração por parte de determinados alunos, os quais, assim como eu, afetados por tudo isso, muitas vezes demonstravam-se cansados.

Os desafios foram vencidos na medida em que fomos nos aproximando e entendendo, juntos, a elaboração das atividades. Os meus alunos foram se sentindo cada vez mais à vontade para apresentar suas práticas de leitura e, principalmente, para falar sobre elas. A teorização vygotskyana de aprendizagem que ancora o processo de aprender no social, na história e na cultura, sendo a linguagem elemento primordial na coconstrução de conhecimentos estava sendo a base dos nossos encontros. Porém, houve uma situação em que um aluno se sentiu constrangido para falar:

Hoje o aluno Naruto levou o livro O Diário de uma Paixão do autor Nicholas Sparks, mas demonstrou estar envergonhado para mostrar o livro para os colegas e me deixar fotografá-lo. Perguntei para ele o porquê de apresentar resistência para mostrar o livro. Naruto me respondeu que estava com vergonha porque os colegas poderiam dizer que ele estava lendo livro de um autor que escreve apenas para mulheres. (Caderno reflexivo da professora, 17 de agosto de 2015)

A partir das questões que se apresentavam, novas diretrizes para a elaboração das atividades eram dadas. Assim como a contribuição de Naruto (nome fictício indicado pelo próprio aluno) 
suscitou discussões e problematizações dentro do grupo, a intervenção da maior parte dos aprendizes neste trabalho, através da fala da aluna Kelsey (nome também fictício indicado pela aluna), representou uma mudança decorrente do processo de construção de autonomia:

Hoje a aluna Kelsey veio me dizer que o assunto de trabalhar com romance surgiu na aula de produção textual e que a professora Cátia queria participar das atividades sobre o gênero romance também. A professora Cátia é fã do autor Nicholas Sparks e Kelsey perguntou para a turma se eles aceitavam trabalhar com livros desse autor já que a maioria lia ou já tinha lido um livro escrito por ele. Kelsey disse que a turma tinha concordado e que faltava eu aceitar. Aceitei. (Caderno reflexivo da professora, 31 de agosto de 2015).

A forma como Kelsey encaminhou a situação e os novos contornos que aquelas atividades estavam ganhando me surpreenderam. A professora Cátia (nome fictício) e eu não tínhamos muito contato. Os meus alunos, envolvidos como agentes no "trabalho para entender", estavam provocando a aproximação entre professores, a fim de que o processo de ensino e de aprendizagem fosse favorecido. Eles se percebiam como agentes da aprendizagem, produtores de conhecimento como Allwright e Hanks (2009) discutem ao apresentar algumas proposições sobre aprendizes. Certamente, as intervenções feitas por eles mesmos tornavam o processo de ensino e de aprendizagem mais significativo. Ademais, o acolhimento das leituras realizadas pelos meus alunos e pelas minhas alunas constituiu o reconhecimento dos letramentos (STREET, 2014; SOARES, 2012) dos aprendizes, de modo que o diálogo multicultural fosse favorecido e as experiências de leitura dos alunos, bem como as leituras valorizadas pelo currículo escolar se tornassem objeto de estudo, de crítica e de reflexão (ROJO, 2009).

Apresento, abaixo, dois pôsteres elaborados pelos aprendizes, os quais constituíram um dos momentos de construção de entendimentos acerca de suas práticas de leitura. Em Prática Exploratória, os praticantes costumam elaborar pôsteres como forma de partilhar seus puzzles e entendimentos. Reserva-se um momento em aula para a produção e, depois, para a apresentação. Assim, a elaboração dos pôsteres bem como a realização das demais atividades produzidas com os aprendizes constituíram momentos de reflexão e de aprendizagem colaborativa.

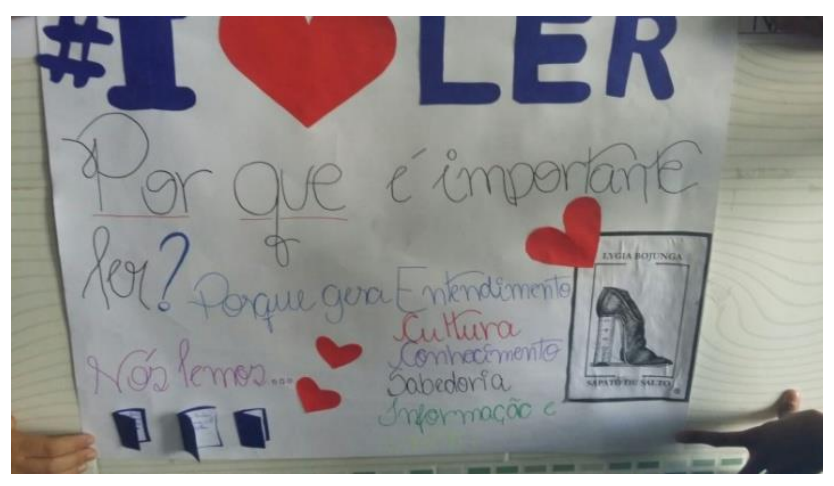

Figura 1: Pôster de um grupo de alunos 


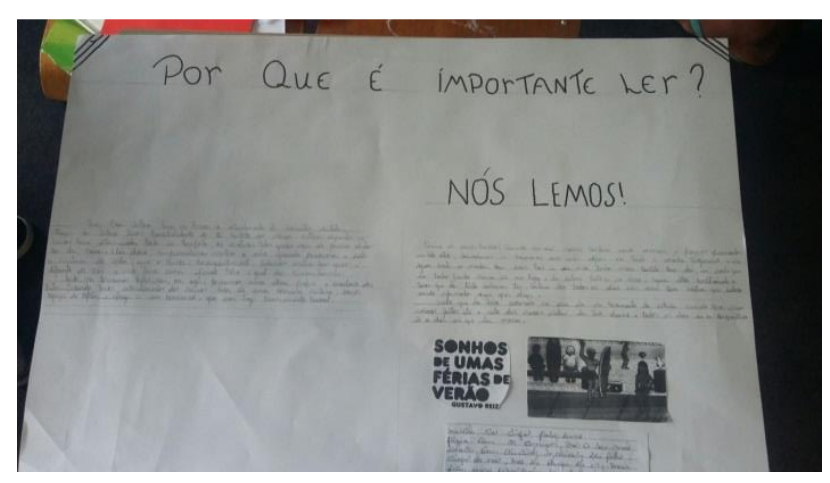

Figura 2: Pôster de um grupo de alunos

Ao valorizar o repertório de leitura dos meus alunos, pude me perceber, de fato, como uma professora pesquisadora praticante exploratória, de tal modo que a fala, "os alunos não gostam de ler", tão comumente escutada nos corredores escolares e entre os professores de língua portuguesa, não ecoou em nossa sala de aula. Pelo contrário, pude ouvir a fala de meus alunos, "Eu gosto de ler". Penso que as atividades elaboradas buscaram o diálogo entre as práticas de leitura dos alunos e os conhecimentos legitimados pelos currículos escolares oficiais. Ademais, uma política de e para a leitura não deve deixar de acolher as diversas formas de expressão literária e de práticas de leitura que os alunos trazem consigo e fazem adentrar o ambiente escolar. Assim, creio que se possibilita aos alunos associar a leitura a entendimento, a ampliação de vocabulário, ao conhecimento, a divertimento e ao prazer da descoberta, em uma percepção da leitura não como um ato solitário, mas como interação, atravessada por nossas relações conosco, com o outro e com o mundo (SOARES, 2005).

\section{Considerações finais}

É possível que sejam levantadas críticas a essa experiência e ao fato de os alunos colocaremse como leitores, alegando-se que eles apenas disseram o que a professora desejava ouvir. Contraponho a essa fala o fato de havermos partido dos interesses de leitura dos aprendizes, valorizando os livros que vinham para a sala de aula, mas que permaneciam nas mochilas porque não havia lugar para eles no conteúdo oficial.

Pode-se considerar ainda que o fato de abrir a sala de aula para outras leituras de textos escritos - que não sejam apenas aquelas valorizadas pelos currículos escolares - não se proporciona, necessariamente, um espaço para a criatividade e para a autonomia. Possíveis posturas e vivências 
relacionadas com o texto escrito podem ser fruto de modismos, de produto da máquina cultural de mercado e da ideologia de consumo. No entanto, acredito que é no apresentar nossos conhecimentos e vivências, no encontro com a alteridade e no diálogo estabelecido entre diferentes conhecimentos e formas de agir no mundo que posturas crítica-reflexivas podem ser fomentadas e é na tessitura de vivências que saberes podem ser ressignificados.

A elaboração e realização dessas atividades constituíram, sobretudo, um momento de reflexão e de transformação de minha prática docente. Essa mudança não foi realizada de maneira técnica e programada, distante da realidade que atravessa o meu fazer pedagógico. Ocorreu considerando tudo o que envolve a minha atividade como professora da escola pública estadual e dos meninos e das meninas das classes populares: desafios diários relacionados com a estrutura da escola, com a falta de material para o trabalho e com as mazelas de uma sociedade doente, as quais atravessam os muros e chegam às salas de aula, transformando a relação professor-aluno. Ter encorajado os meus alunos para a elaboração e a realização dessas atividades constituiu um momento de geração de dados da pesquisa, mas, igualmente, uma oportunidade de reflexão sobre minha formação continuada.

Acredito que valorizar o que alunos e professora leem, o que escrevem, valorizar as suas contribuições, as suas percepções, os seus entendimentos talvez seja o caminho a ser construído para que as diferentes expectativas que atravessam o ambiente escolar não fiquem no obscurantismo que gera sofrimento, mas ganhem o primeiro plano, contribuindo para uma lógica de tolerância, respeito à diversidade e de possibilidades de acesso a conhecimentos outros. Ressalto que esse estudo não desejou exaltar determinadas práticas escolares com relação ao trabalho com a leitura e criticar outras. 0 intuito da pesquisa foi o de suscitar reflexões a respeito de uma temática que parece ser conduzida por discursos cristalizados no ambiente escolar.

Ademais, desejou-se apresentar possibilidades para o trabalho com um tema que gera inquietações em muitos professores e alunos. Dessa forma, buscou-se apresentar possibilidades de trabalho com uma temática por meio de uma interlocução honesta com os alunos. E, como afirma Geraldi (2012, p. 99): "honesta, aqui, não tem nenhum sentido moralista. Honesta porque só se concretizará com o outro-leitor que o complementará por sua palavra".

\section{Creating knowledge and building understandings about reading practices under the Exploratory Practice}

\footnotetext{
Abstract: In this article, I present a piece of my Master's research, in which I aimed, as building a collaborative learning movement with my students, working to understand the reading practices of the learners. This study is based in the beacon principles of Exploratory Practice (ALLWRIGHT, 2005) and in the postulated teory by Vygotsky (2003), as it highlights the inportance of interaction of individuals in the process of teaching-learning. This research points to the fact that the activities that boost the reader's development must considerate not only the work with the language (TRAVAGLIA, 2009) and with the discursive genres (BAKHTIN, 2011), but also
} 
needs to promote the dialog between the multiples coexisting knowledges inside the school environment, so that not only the hegemoniac understanding takes place inside the classroom.

Key words: Reading. Exploratory Practice. Pedagogical Activity with Exploratory Potential. Speech.

\section{Referências}

ABREU, M. As variadas formas de ler. In: Aparecida Paiva et al. (org). No fim do século: a diversidade: o jogo do livro infantil e juvenil. Belo Horizonte: Autêntica, 2000.

ALLWRIGHT, D. et al. From teaching points to learning opportunities and beyond. Tesol Quarterly, Lancaster, mar. 2005.

ALLWRIGHT, D.; HANKS, J. I The Developing language learner: An introduction to exploratory practice.London: Palgrave Macmillan, 2009.

BAKTHIN, M. Estética da criação verbal. Tradução de Paulo Bezerra. São Paulo: M. Fontes, 2011.

DENZIN, N. K., LINCOLN, Y.S. A disciplina e a prática da pesquisa qualitativa. In: $O$ Planejamento da Pesquisa Qualitativa: Teorias e abordagens. Porto Alegre: ARTMED, 2006.

FERRAÇO, C.E. Currículo, cotidiano escolar e conhecimentos em redes. In: Pacto Nacional pela Alfabetização na Idade Certa. Currículo na perspectiva da inclusão e da diversidade: as diretrizes Curriculares Nacionais da Educação Básica e o ciclo de alfabetização. Caderno 1. Ministério da Educação, Secretaria de Educação Básica, Diretoria de Apoio à gestão Educacional - Brasília: MEC, SEB, 2015.

GERALDI, J. W. (Org.). O texto na sala de aula. São Paulo: Anglo, 2012.

MILLER et al. Questões, questões e mais questões: a Prática Exploratória e o trabalho para entendêlas em momentos de transformação. Oficina de Prática Exploratória. Evento vinculado ao Mestrado Profissional em Letras-UERJ e ao NEPPE, maio. 2016, handout.

MORAES BEZERRA, I. C. R.; MILLER, I. K.; CUNHA, M. I. A. . Prática de Ensino e Prática Exploratória: oportunidades para buscar compreender a vida no cotidiano escolar. In: Helena Amaral da Fontoura. (Org.). Diálogos em Formação de Professores: pesquisas e práticas, Niterói: Intertexto, 2007.

MORAES BEZERRA, I. C. R. Prática exploratória e a formação inicial do professor reflexivo: "O que vai ficar para os alunos?". In: Revista Contemporânea de Educação. Volume 7, n. 13, Janeiro/Julho, Rio de Janeiro, 2012.

REGO, T.C. Vygotsky: uma perspectiva histórico-cultural da educação. Petrópolis, RJ: Vozes, 1995.

ROJO, R. Letramentos múltiplos, escola e inclusão social. São Paulo: Parábola, 2009.

SOARES, M. As condições sociais da leitura: uma reflexão em contraponto. In: ZILBERMAN, R.; SILVA, E. T. da.Leitura: perspectivas interdisciplinares. São Paulo: Ática, 2005.

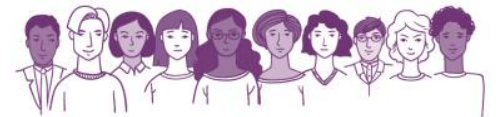


M. Letramento: um tema em três gêneros. 3a ed. Belo Horizonte: Autêntica, 2012.

STREET, B. V. Letramentos sociais: Abordagens críticas do letramento no desenvolvimento, na etnografia e na educação. Tradução de Marcos Bagno. RJ: Parábola, 2014.

TRAVAGLIA, L. C. Gramática e Interação: uma proposta para o ensino de gramática. São Paulo: Cortez, 2009.

VYGOTSKY, L. S. A formação social da mente: o desenvolvimento dos processos psicológicos superiores/ L. S. Vygotsky; organizadores Michael Cole et al; tradução José Cipolla Neto, Luís Silveira Menna Barreto, Solange Castro Afeche. 6ạ ed. São Paulo: M. Fontes, 2003. 